\title{
DIRETRIZES POLÍTICAS PARA O PERFIL DE PROFESSORES NO CONTEXTO DA REFORMA DO ESTADO: UMA ANÁLISE DAS RECOMENDAÇÕES DA UNESCO
}

\author{
Carlos Vinicius Ramos ${ }^{1}$, Jani Alves da Silva Moreira² \\ ${ }^{1}$ Mestre em Educação no Programa de Pós-graduação em Educação (PPE) da Universidade Estadual de Maringá - \\ UEM, Maringá, PR. E-mail: viniramos91@hotmail.com \\ ${ }^{2}$ Doutora em Educação pela Universidade Estadual de Maringá - UEM. Professora Adjunta do Departamento de Teoria \\ e Prática Educação e do Programa de Pós-Graduação em Educação da Universidade Estadual de Maringá - UEM, \\ Maringá, PR.
}

\section{RESUMO}

O objetivo do texto é analisar e identificar quais as recomendações advindas da Organização das Nações Unidas Para a Educação a Ciência e a Cultura (UNESCO) para a configuração da profissão de professor, a partir da reforma do Estado na década de 1990, a fim de evidenciar o perfil e o modelo que se consolidaram para esta profissão no Brasil. Verifica-se recomendações, especificamente, os discursos utilizados e os objetivos destes pronunciamentos pela análise documental de relatórios divulgados pela Unesco. A pesquisa contribuiu para que entendamos de que forma as consequências da reforma do Estado passaram a influenciar como os professores devem trabalhar por meio da otimização de investimentos a fim de serem mais produtivos e gerarem resultados eficazes no processo escolar.

Palavras-chave: Políticas para formação de professores. Reforma do Estado. Educação. Profissionalismo docente. Unesco.

\section{POLICY GUIDELINES FOR TEACHERS' PROFILE IN THE CONTEXT OF STATE REFORM: AN ANALYSIS OF UNESCO RECOMMENDATIONS}

\begin{abstract}
This text aims to analyze and identify the recommendations of the United Nations Educational, Scientific and Cultural Organization (UNESCO) for the configuration of the teaching profession, from the state reform in the 1990s, for the purpose of evidence the profile and the model that were consolidated for this profession in Brazil. Recommendations are checked, specifically, the speeches which are used and the objectives of these statements by the documentary analysis of reports that are published by Unesco. The research contributed so that we understand how the consequences of the reform of the State began to influence how teachers should work by optimizing investments with the view to be more productive and engender effective results in the school process.
\end{abstract}

Keywords: Policies for teacher training. Reform of the State. Education. Teaching professionalism. Unesco.

\section{INTRODUÇÃO}

O presente texto tem como objetivo analisar a relação de como se define a agenda política para o perfil de professores, por meio de estudos dos relatórios oficiais e das diretrizes políticas de organismos internacionais, no caso específico da Unesco. Identificamos e analisamos quais foram as principais recomendações políticas da Unesco no contexto da reforma do Estado e, ainda, averiguamos como as suas diretrizes políticas influenciaram no perfil e modelo de professor no Brasil, a partir da década de 1990.

Consiste em apresentar neste texto a compreensão acerca das características principais da reforma do Estado, sobretudo nas décadas de 1990, suas bases materiais, objetivos e correlacionar sua influência com as orientações presentes em documentos internacionais que refletem nas políticas para os professores no Brasil, especificamente no que tange ao seu perfil. 
Os pronunciamentos propalados como recomendações dos Organismos Internacionais, entre eles a Organização das Nações Unidas para a Educação a Ciência e a Cultura (UNESCO), marcam uma época em que a educação passa a ser central na reestruturação do Estado em 1990. Eles prescrevem orientações políticas aos países emergentes de como sobressair bem educacionalmente sobre uma retórica hegemônica e econômica que busca seguir os modelos de reforma educacional de países desenvolvidos.

Ao analisarmos as propostas políticas da Unesco para o perfil de professores no contexto neoliberal, partimos do princípio que a historicidade e o papel do Estado são questões fundamentais para que saibamos os pressupostos de sua reforma e, consequentemente, as mudanças decorridas na educação neste período. Mascaro (2013) analisa que o modelo do Estado atual está inserido na própria dinâmica estrutural do capitalismo. O Estado é capitalista devido à sua construção histórica dotada de mecanismos que permitiu e permite a perpetuação deste sistema.

A organização estatal, como conhecemos hoje, surgiu na idade moderna após o período das grandes revoluções burguesas, em meados do século XVIII. Salienta Mascaro (2013, p.61) que desde este período das revoluções, os representantes do governo não coincidem mais com os donos da produção da riqueza material, quem governa o Estado é um poder distinto "da imediatitude dos domínios de classes, grupos ou indivíduos", mas o fato dos governantes não serem os grandes empresários capitalistas da sociedade, nem por isso o Estado se torna um elemento neutro na relação econômica de dominação entre proletários e burguesia. Como pondera:

Diferentemente das visões tradicionais, que acusam o Estado de ter um caráter burguês porque o domínio de suas instituições está supostamente sendo feito por agentes ou representantes do interesse burguês, o Estado é capitalista porque sua forma estrutura as relações de reprodução do capital. Por isso, deve-se entender a ligação entre Estado e capitalismo como intrínseca não por razões de um domínio imediato do aparelho estatal pela classe burguesa, mas sim por razões estruturais. Em vez de se apresentar como um instrumento político neutro, então ocasionalmente dominado pelas classes burguesas, o Estado é um elemento necessário nas estruturas da reprodução capitalista (MASCARO, 2013, p.59).

Nesta reprodução, o Estado aparece como um ente terceiro não sendo governado nem pela classe da burguesia e nem pelos próprios proletários. Ele serve como um aparato para regular a relação dos indivíduos às classes e desta maneira "o Estado se consolida como um ente terceiro, garante e necessário da dinâmica do capitalismo. Em face dos indivíduos e suas interações, que passam a identificar a "vida privada", o Estado se inscreve como distinto: "público" (MASCARO, 2013, p.57), ele serve, portanto, como arena de um campo de luta, no qual, as diferentes classes irão colidir e buscar cada qual o seu interesse.

Para Paulo Netto e Braz (2012) o sistema capitalista está fadado às constantes crises econômicas que fazem parte da própria dinâmica do capital. Mediante os autores, a crise não é um "acidente de percurso, não é aleatória", mas constitutiva do capitalismo; "não existiu, não existe e não existirá capitalismo sem crise" (PAULO NETTO; BRAZ, 2012 p.170). No bojo desse contexto, o Estado está em processo, também, de transformação constante e para tentar conter a crise redimensionam o seu papel frente à economia, ora com mais presença e intervenção ao sistema financeiro (política do bem estar social), ora de maneira mais distante dos trâmites econômicos-social (liberalismo/neoliberalismo).

Um marco importante das propostas de reforma aconteceu em 1989, sob o comando do Banco Mundial, na cidade de Washington nos EUA, onde economistas se reuniram para encontrar respostas à crise que estavam vivendo os países Latino Americanos. Nesta reunião chegaram à conclusão de que a causa da crise na América Latina era decorrente da excessiva atuação do Estado-providência do bem-estar 
social e a forte regulação que não continha mais as artimanhas necessárias para um mundo de grande concorrência internacional sobre a influência da globalização. As resultantes deste encontro ficaram conhecidas como "consenso de Washington". Nesta discussão e:

$$
\begin{aligned}
& \text { De acordo com a } \\
& \text { abordagem de } \\
& \text { Washington as causas da } \\
& \text { crise latino-americana são } \\
& \text { basicamente duas: a) } 0 \\
& \text { excessivo crescimento } \\
& \text { econômico do Estado, } \\
& \text { traduzido em } \\
& \text { protecionismo (o modelo } \\
& \text { de substituição de } \\
& \text { importações), excesso de } \\
& \text { regulação e empresas } \\
& \text { estatais ineficientes e em } \\
& \text { número excessivo; e b) o } \\
& \text { populismo econômico, } \\
& \text { definido pela incapacidade } \\
& \text { de controlar o déficit } \\
& \text { público e de manter sob } \\
& \text { controle as demandas } \\
& \text { salariais tanto do setor } \\
& \text { privado quando do setor } \\
& \text { público (PEREIRA, 1991, } \\
& \text { p.5). }
\end{aligned}
$$

Identificado o suposto problema, uma série de ações e orientações são elaboradas para que os países retornassem ao crescimento econômico e pudessem competir no âmbito internacional. Dentre as soluções estavam "Promover a estabilização da economia através do ajuste fiscal e da adoção de políticas econômicas ortodoxas em que o mercado desempenhe o papel fundamental" (PEREIRA, 1991 p.6). Inicia-se um conjunto de reformas que tentam conter o populismo econômico e incentivar as políticas de privatizações. De acordo com Harvey (2011) é neste cenário que tem início uma longa era de "ajustes estruturais" por recomendações dos Organismos Internacionais, como a Unesco e também das agências financeiras, sobretudo o Banco Mundial (BM), o Banco Interamericano de Desenvolvimento (BID) e o Fundo Monetário Internacional (FMI).

A crise do capitalismo iniciado na década de 1980 afetou toda parte do mundo com a maior ênfase principalmente nos países em desenvolvimento. Algumas mudanças estratégicas para tentar conter a crise fizeram os países redefinirem a posição e a forma de ser e do Estado administrar, mudando assim, as suas intervenções político-econômicas. Neste sentido:

O Estado foi demonizado pelos neoliberais $e$ apresentado como um trambolho anacrônico que deveria ser reformado - e, pela primeira vez na história do capitalismo de mudanças para ampliar direitos; a partir dos anos oitenta do século XX, sob o rótulo de reformas(s) o que vem sendo conduzido pelo grande capital é um gigantesco processo de contra-reforma(s),

destinado à supressão ou redução de direitos e garantias sociais (PAULO NETTO; BRAZ, 2012, p.239).

Abre-se um caminho ao voluntariado que desobriga o Estado de uma série de contratantes e servidores: Uma das inovações fundamentais se vincula com a importância que "crescentemente adquirem as formas de propriedade e de controle social públicos não-estatais, a ponto em que é possível presumir que o século $X X I$ será o século onde o público não-estatal poderá constituir-se numa dimensão chave da vida social" (PEREIRA; GRAU, 1999, p.16). O que se espera nesta mudança é que se faça relações com a própria sociedade para que esta execute os serviços que deveriam ser garantidos pelo Estado, cresce as instituições como os Organismos não Governamentais que ofertam acesso à educação, saúde, cultura. Conforme preconiza os autores que:

A reforma do Estado que está ocorrendo nos anos 90, deverá conduzir a um Estado fortalecido, com suas finanças recuperadas e, com sua administração obedecendo à critérios gerenciais de eficiência. Mas a reforma também deverá alcançar o asseguramento pelo Estado que as atividades sociais, que não são monopolistas por natureza, sejam realizadas competitivamente pelo setor público não-estatal 
e por ele controladas ainda que com seu apoio financeiro, de maneira a conseguir a ampliação dos direitos sociais (PEREIRA; GRAU, 1999, p.17, grifos do autor)

Essa parceria entre público e privado dá a educação um vocabulário de competitividade advindo do empresariado, pois as reformas estão atreladas à lógica de mercado. As escolas passam a ter uma gestão mais autônoma e de maiores responsabilidades, de maior participação da comunidade no qual o professor está atrelado nesta perspectiva como um grande líder na promoção destas tarefas.

A partir da década de 1990 instituiu-se uma fase em que o capitalismo atingiu sua etapa imperialista/monopolista com o processo de globalização em que os países centrais avançam sobre os periféricos mediante o ideário do neoliberalismo e suas políticas de ajustes estruturais (PAULO NETTO, BRAZ, 2012). Nesta conjuntura, a educação teve um papel estratégico que auxilia na implantação deste ideário neoliberal de promoção da liberdade do mercado, crescimento econômico e passa a ser mediada pelas análises dos grandes organismos internacionais, como também financiada por bancos internacionais.

Nesta fase do capital, o estudo é conceituado como uma formação vantajosa para investimento pessoal e econômico. Pesquisas divulgam que quanto mais se investe em educação, maior é o crescimento econômico de determinado país ${ }^{1}$. Nesta visão, a aprendizagem deixa de ser um instrumento que forma o jovem para a compreensão integral da vida, inserindo-o apenas em toda complexidade e realidade desigual da sociedade para se relacionar em um mundo competitivo voltado ao livre mercado.

À educação sobrevém um papel estratégico com grande atenção e prioridade das recomendações dos Organismos Internacionais para que os países se tornem mais competitivos à modelo dos países centrais.

\footnotetext{
${ }^{1}$ A Organização para a Cooperação e Desenvolvimento Econômica (OCDE) "argumenta que melhorar o padrão da educação impulsionará o crescimento econômico dos países. E afirma que o baixo nível da educação em um país pode resultar num "estado permanente de recessão" (BBC, 2015). Disponível em: <http://www.bbc.com/portuguese/noticias/2015/05/150512_ educacao_mapas_cc> Acesso em: 23.fev.2017.
}

Diante do contexto apresentado, o objetivo deste trabalho é identificar e analisar quais foram as principais recomendações políticas da UNESCO no contexto da reforma do Estado e ainda, averiguar como as suas diretrizes políticas influenciaram no perfil e modelo de professor no Brasil, a partir da década de 1990.

\section{METODOLOGIA}

Trata-se de uma análise documental para compreendermos a relação de como se define a agenda política para o perfil de professores, por meio de estudos dos relatórios oficiais e das diretrizes políticas de organismos internacionais, no caso específico da UNESCO.

As recomendações documentais no campo do estudo de políticas educacionais de acordo com Shiroma, Campos e Garcia (2005, p. 430-431):

Não são prontamente
assimiláveis ou aplicáveis.
Sua implementação exige
que sejam traduzidas,
interpretadas, adaptadas
de acordo com as
vicissitudes e os jogos
políticos que configuram o
campo da educação em
cada país, região,
localidade; tal processo
implica, de certo modo,
uma reescritura das
prescrições, o que coloca
para os estudiosos a tarefa
de compreender a
racionalidade que os
informa e que, muitas
vezes, parece
contraditória, fomentando
medidas que aparentam ir
em direção contrária ao
que propõem.

Verificam-se recomendações, especificamente, os discursos utilizados e os objetivos destes pronunciamentos em quatro documentos internacionais:

- A Declaração Mundial de Educação para todos (UNESCO, 1990)

- O Relatório para a Unesco da Comissão Internacional sobre Educação para o século XXI: Educação, um tesouro a descobrir (UNESCO, 2010)

- $\quad$ Educação para Todos: O Compromisso de Dakar (UNESCO, 2000) 
- O Desafio da Profissionalização Docente no Brasil e na América latina (UNESCO, 2007).

A escolha destes documentos da Unesco se deu por serem redigidos no contexto da reforma do Estado (após 1990), terem influências nas diretrizes educacionais brasileira, são relatórios que tratam da educação e discutem a questão dos profissionais da educação.

\section{RESULTADOS E DISCUSSÃO}

Ao apresentar os resultados e discussão dispomos no primeiro momento a análise do documento resultante da Conferência Mundial de Educação de 1990, a Declaração Mundial de Educação para todos, inserida na ideologia neoliberal e de reforma do Estado. Em seguida, verificaremos a concepção do professor com base no Relatório Delors e, por fim, faremos uma reflexão acerca do papel do docente, neste contexto histórico de mudanças, tendo por referência o Compromisso de Dakar e o documento Desafio da Profissionalização Docente no Brasil e na América Latina.

\section{UNESCO e suas recomendações na Conferência Mundial de Educação}

Em 1990, realizou-se a Conferência Mundial de Educação para todos em JomtienTailândia, na qual foi um marco para as propostas de mudanças educacionais. A reunião teve como objetivo "oferecer diretrizes à redefinição das políticas públicas dos países membros da ONU no âmbito da Educação" (DAMÁSIO, 2008, p. 10). Ao analisar o documento resultante, a Declaração Mundial de Educação para todos de 1990, é possível evidenciar em seu capítulo sete (7) denominado "fortalecer as alianças", a seguinte recomendação: trabalho, comunicações, e outros setores sociais; entre as organizações governamentais e não governamentais, com $\mathrm{o}$ setor privado, com as comunidades locais, com os grupos religiosos, com as famílias. É particularmente importante reconhecer o papel vital dos educadores e das famílias (UNESCO, 1990, p.5)

Como podemos observar a declaração incentiva à formação de parcerias com entidades privadas e a sociedade civil, com o intuito de legitimar as propostas e recomendações da reforma do Estado. Também evidenciado no artigo nono da Declaração que orienta que para que sejam satisfeitas as necessidades básicas de aprendizagem "será essencial mobilizar atuais e novos recursos financeiros e humanos, públicos, privados ou voluntário" (UNESCO, 1990, p.6).

Roger Dale (2004) ao falar da Agenda Globalmente Estruturada para educação (AGEE) estabelece que a educação tenha sido influenciada por um sistema de controle de forças econômicas supranacionais que regem nossa política educacional, ações de governanças, que devem ser questionadas e pensadas "como a quem é ensinado o quê, como, por quem e em que circunstâncias? Como, por quem e através de que estruturas, instituições e processos são definidas estas coisas" [...] (DALE 2004, p. 439). Estas perguntas devem ser feitas para entender como que as estruturas e processos vão afetar a vida de indivíduos em diversas relações com os sistemas educativos. Para o autor:

Estas questões centram-se nos princípios e processos da distribuição da educação formal, na definição, formulação, transmissão e avaliação do conhecimento escolar e em como é que estas coisas se relacionam entre si. Elas dirigem-nos no sentido de descobrir como é que aqueles processos são financiados, fornecidos e regulados e como este tipo de formas de governação se relacionam com 
concepções mais amplas de governação dentro de uma sociedade (DALE, 2004, p. 439).

Cabe evidenciar que os processos de transformações sociais, políticos e econômicos são imprescindíveis para conhecer os objetivos propostos para a educação, e na atual conjuntura capitalista monopolista de globalização internacional entender os processos de reforma do Estado. O Brasil está inserido dentro das reformas voltados aos países no conjunto da América Latina. Gajardo (2000) divide as reformas educacionais, da década de 1990, em torno de quatro eixos de políticas que foram de atuação estratégica para a inserção de novos programas da reforma: o da gestão, o da qualidade e equidade, o do aperfeiçoamento docente e o do financiamento. Neste sentido:

Enquanto o primeiro e o último apontam para a racionalização de recursos, a descentralização da administração do sistema e dos estabelecimentos, bem como para a avaliação do rendimento escolar, os demais eixos voltam-se para a necessidade de contar com escolas eficazes, que usem os insumos existentes da melhor maneira, enfatizem os resultados acadêmicos, imponham um sistema ordenado em termos de assistência, infraestrutura e insumos educativos $e$ fortaleçam a capacidade de liderança e gestão de diretores e professores (GAJARDO, 2000, p.8).

No que se refere à gestão, a autora constatou uma tendência à descentralização administrativa e pedagógica para as diferentes instâncias governamentais que minimizou a responsabilidade do Estado para as instâncias locais, com uma maior autonomia escolar e participação local. No que se refere em relação de equidade, o que se vê, são políticas focalizadas em escolas do nível básico com condições mais carentes, discriminação para grupos vulneráveis como pobres, indigentes urbanos e rurais, indígenas, mulheres e crianças. E quanto ao aperfeiçoamento de professores o que se tem é uma política de incentivos, por metas e uma remuneração por desempenho.

Contudo, as adoções de mecanismos de mercado nas políticas estatais passam a estimular a competição, premiação por resultados, concessão de subsídios, focalização nos resultados, maior flexibilidade, descentralização e maior autonomia das instituições. O discurso em geral dos documentos utiliza-se da noção de crise como uma retórica importante nas mudanças educacionais e "para enfrentar a crise, miram-se nas estratégias e importam o vocabulário de um setor acostumado a deparar-se com ela e a vencê-la: o empresariado" (SHIROMA; CAMPOS; GARCIA, 2005, p.438).

Entre as palavras mais utilizadas como gerencialismo, recursos, eficiências, estão constantemente presentes nos documentos internacionais. São atribuídas metas e a racionalização do recurso que fazem com que os gestores tentem fazer "mais com menos" recurso. Ao professor cabe atribuições diversas, como: de gestor, líder de problemas cotidianos educacionais, o que the exige criatividade para conseguir trabalhar com poucos recursos.

No Brasil, em 1995 foi enviado ao Congresso Nacional o Plano Diretor da Reforma do Aparelho do Estado. Em suas propostas estão em consonância a essas indicações da crise e propõe transferir para as entidades privadas serviços que podem ser executados por eles e propõe, além disso, que o Estado deveria estar aberto a um regime de parcerias com a sociedade civil. "Através de um programa de publicização, transfere-se para o setor público não-estatal a produção dos serviços competitivos ou nãoexclusivos de Estado, estabelecendo-se um sistema de parceria entre Estado e sociedade" (BRASIL, 1995, p. 13).

$\mathrm{Na}$ tentativa de desregulamentar a economia e trazer um agente de terceiro setor para a execução de serviços, obrigações que por lei eram do Estado, passam a ser de outros, obrigações que inclui a prestação de serviços essenciais como a segurança, saúde e a educação.

Deste modo o Estado
reduz seu papel de
executor ou prestador
direto de serviços,
mantendo-se entretanto
no papel de regulador e


provedor ou promotor destes, principalmente dos serviços sociais como educação e saúde, que são essenciais para 0 desenvolvimento, na medida em que envolvem investimento em capital humano (BRASIL, 1995, p. 13 , grifo do autor).

Chamamos a atenção para a palavra "promotor" no excerto acima, pois compreendese que o Estado deve promover e incentivar com publicidades a propagação do serviço social para que a própria sociedade num ato de caridade se encarregue de executá-los. Essa parceria entre público privado dá a educação um vocabulário de competitividades advindo do empresariado, as reformas estão atreladas a lógica de mercado. As escolas passam a ter uma gestão mais autônoma e de maiores responsabilidades, de maior participação da comunidade, na qual o professor está atrelado nesta perspectiva como um grande líder na promoção destas tarefas.

Salientamos que o professor foi 0 principal sujeito envolvido nestas mudanças e o profissional que mais sofreu as consequências diretas, "a reforma dos anos de 1990, e seu prosseguimento no novo século, atingiu todas as esferas da docência: currículo, livro didático, formação inicial e contínua carreira, avaliação e gestão" (EVANGELISTA; SHIROMA, 2007, p.537). As orientações dos documentos trazem mudanças quanto a projetos pedagógicos de investimento do Estado, do papel da escola, as funções do ensinar e aprender, entre outros.

\section{Relatório Delors e a concepção de professor}

No fim do século $X X$ foi elaborado pela Unesco, o Relatório da Comissão Internacional sobre Educação para o século XXI: Educação, um tesouro a descobrir (UNESCO, 2010), este é um documento que possui uma grande influência nas configurações da política brasileira. Chama a atenção o capítulo denominado "os professores em busca de novas perspectivas" que trata de assuntos relacionados com a função do professor e expressa que:

Mesmo que ofício de
professor
fundamentalmente, uma
atividade solitária, no
sentido de que cada
professor deve assumir

suas

próprias

responsabilidades $\mathrm{e}$ deveres profissionais, o trabalho em equipe é indispensável, sobretudo no secundário, para melhorar a qualidade da educação e adaptá-la às características particulares das aulas ou dos grupos de alunos" (UNESCO, 2010, p.34).

Podemos perceber que nessa recomendação, o trabalho em equipe, a descentralização de funções passaram a ser exigências para a profissão docente. Moreira (2015) ao analisar o Relatório apresenta que as prioridades do documento estão em definir a educação básica como foco do investimento público, além disso, o documento "apresenta uma série de sugestões que se concentram nas diretrizes para a equidade, responsabilidade social e eficiência" (MOREIRA, 2015, p.218). documento Dellors (2010) ao reconhecer a profissão de professores entende este agrupamento como uma entidade dotada de experiência que tem o conhecimento da causa dos docentes:

\begin{tabular}{|c|}
\hline $\begin{array}{l}\text { Todas essas orienta } \\
\text { devem ser objeto } \\
\text { diálogo, até mesmo } \\
\text { contratos, com } \\
\text { organizações } \\
\text { professores, passando } \\
\text { cima do car } \\
\text { puramente corporati } \\
\text { de tais negociações. } \\
\text { fato, as organiza } \\
\text { sindicais, além do obje } \\
\text { de defender os intere } \\
\text { morais e materiais de } \\
\text { associados, acumula } \\
\text { um capital } \\
\text { experiências; } \\
\text { dispõem-se a transı } \\
\text { esse acervo } \\
\text { responsáveis } \\
\text { decisões polí } \\
\text { (UNESCO, 2010, p.35). }\end{array}$ \\
\hline
\end{tabular}

O fato de o documento se preocupar com as negociações dos sindicatos mostra a preocupação do Relatório em saber como se dá a formação da classe docente enquanto resistência e quais os parâmetros utilizados por estes. O modelo adotado pelas recomendações propõe à 
centralização das decisões de política educacional, de regulamentação e de avaliação dos sistemas. Separam o papel do professor elaborador de ideias e de planejamento, ele passa ser uma agente da execução das propostas governamentais com responsabilidades de gestão local. Os professores de maneira geral não participam das tomadas de decisões macro que vêm prontas das instâncias maiores. Neste novo quadro de gestão local o professor passa a ter funções que ultrapassa suas ações pedagógicas de ensinar:

O professor, diante das variadas funções que a escola pública assume, tem de responder a exigências que estão além de sua formação. Em contexto de demasiada pobreza, como é o caso dos países latinoamericanos, os professores vêem-se obrigados a desempenhar funções que estão além da tarefa educativa, do ato de ensinar. São compelidos, em dadas circunstâncias, a assumirem os papéis de agente público, assistente social, enfermeiro, psicólogo, entre outros (OLIVEIRA, 2005 p. 769).

O Relatório Delors da Unesco (2010) advém de um conjunto de propostas que vendo sendo feito para a educação na América Latina como um todo. Evangelista e Shiroma (2007), ao analisarem sobre três grandes projetos para a Educação na América Latina e no Caribe: o Proyecto Regional de Educación para a América Latina y el Caribe; O Plan de Cooperación, resultante das Cumbres Iberoamericana de Educación e os Proyectos hemisféricos em educación diz que as reformas têm em vista produzir "um professor com inúmeros elementos em comum, instrumentalizado com objetivos assemelhados" (EVANGELISTA; SHIROMA, 2007 p.533). Ou seja, procuram os documentos formar um professor global adepto os trâmites do capital, sem o mínimo de criticidade da sua realidade histórica e local.

Nesses projetos, também se difunde uma imagem do professor corporativista; avesso às mudanças; acomodado pela rigidez da estrutura de cargos e salários da carreira docente; desmotivado, pois não há diferenciação por mérito, por desempenho, ou seja, como obstáculos à reforma (EVANGELISTA; SHIROMA, 2007, p. 536). Para as autoras ainda essa reforma educacional tem pouco a ver com as questões propriamente educativas e, muito mais, com a busca de uma nova governabilidade da educação pública. "A governabilidade, na área educacional, constrói-se, então por duas vias: profissionalização docente e implementação do gerencialismo nas escolas" (EVANGELISTA; SHIROMA, 2007, p.536).

\section{Os Compromissos de Dakar e os Desafios da Profissionalização Docente no Brasil e na América Latina}

Outra referência de relevância no âmbito da educação elaborado pela Unesco foi o documento Compromisso de Dakar (2000). Esse relatório foi elaborado com objetivo de alcançar os objetivos e as metas de Educação para Todos (EPT). São reafirmados o compromisso da Declaração Mundial para Todos em 1990, assim como avaliar os resultados conquistados, desde então. Na apresentação da carta a educação é compreendida como:

Um direitor humano
fundamental e constitui a
chave para um
desenvolvimento
sustentável, assim como
para assegurar a paz e a
estabilidade dentro de
cada país e entre eles e,
portanto, meio
indispensável para
alcançar a participação
efetiva nas sociedades e
economias do século XXI
afetadas pelar rápida
globalização. Não se pode
mais postergar esforços
para atingir as metas de
EPT. As necessidades
básicas da aprendizagem
podem e devem ser
alcançadas com urgência
(UNESCO, 2000, p.8).

Entende ainda que os professores são essenciais na promoção da educação de qualidade, quer nas escolas ou em programas comunitários mais flexíveis, "são defensores e catalisadores da mudança. Nenhuma reforma educacional será bem-sucedida sem a 
participação ativa e a preponderância dos professores" (UNESCO, 2000, p.24).

No que se refere à remuneração de professores salienta que estes devem ser respeitados em todos os níveis da educação e adequadamente recompensados, também terão "[...] acesso à formação e ao desenvolvimento e ao apoio profissional permanente, inclusive mediante o ensino aberto e a distância; e ser capaz de participar; local e nacionalmente, das decisões que afetam a vida profissional e ambiente de ensino" (UNESCO, 2000, p.24).

Segundo o documento devem ser implantadas estratégias claramente definidas e mais imaginativas para identificar, atrair, capacitar e reter bons professores. Salienta ainda que essas estratégias devem preparar os professores para capacitar os alunos para uma economia emergente, baseada nos avanços das tecnologias. "Os professores devem ser capazes de compreender a diversidade de estilos de aprendizagem e de desenvolvimento físico e intelectual dos estudantes e criar ambientes de aprendizagem estimulantes e participativos" (UNESCO, 2000, p.25).

Dando sequência nas análises, outro documento publicado pela Organização e que trata da questão dos professores é $O$ Desafio da Profissionalização Docente no Brasil e na América Latina (2007) $)^{2}$. O texto nele redigido inicia ressaltando que a América Latina está bem próxima de universalizar o acesso à educação básica, mas continua longe de vencer o desafio da qualidade. Para o relatório o foco estratégico para melhorar os desafios do ensino no século XXI estaria em:

(1) maior flexibilidade das leis e das normas; (2) maior ênfase nas competências e habilidades do que nos conteúdos informativos; prática docente que atenda a todos em sua diversidade; (3) escola que se responsabilize pelos resultados da aprendizagem dos alunos, e na qual a participação e a deliberação coletiva são

\footnotetext{
2“Esta publicação editada com o especial apoio da Representação da UNESCO no Brasil registra as principais discussões realizadas durante o Seminário Internacional de Profissionalização Docente, realizado no Rio de janeiro, nos dias 31 de agosto a 2 de setembro de 2006" (UNESCO, 2007, p.8).
}

a tônica da gestão; (4) e, por fim, sociedade que priorize a educação como fundamental para o desenvolvimento humano, político, social e econômico do país (UNESCO, 2007, p.20).

0 professor de acordo com o relatório deve ser um profissional reflexivo, comprometido com as mudanças, protagonista na elaboração das propostas educacionais e dotado de novas competências que the tenham a flexibilidade necessária para atender alunos diversos e adaptar-se às novas situações que a sociedade, em permanente transformação, lhe propõe.

0 documento ressalta que nesse contexto, a escola deve mudar, transformando-se numa instituição com gestão democrática e participativa, numa comunidade de aprendizagem de todos: alunos e professores, "nessa escola, dotada de autonomia, a busca permanente da eficácia e da eficiência deve decorrer de um sistema de avaliação integral da instituição, dos seus profissionais e do desempenho escolar dos alunos" (UNESCO, 2007, p.21). Essa avaliação é a base para a tomada de decisões, a definição de prioridades, o planejamento e a responsabilidade pelos resultados da aprendizagem. Sobre a avaliação por desempenho, salienta o documento que:

É quase unanimidade nos países a ideia de desenvolver sistemas de carreira e avaliação de desempenho docente. As diferentes decisões dos países decorrem de dois fatores: tradição educacional e prioridades educacionais.

Independentemente das estratégias adotadas, os países têm como objetivos: atrair os melhores candidatos e mantê-los na docência até a aposentadoria; e elevar a qualidade da docência e, como corolário, do ensinoaprendizagem.

As experiências internacionais endossam as seguintes recomendações: um sistema de avaliação de desempenho deve ser 


\begin{abstract}
construído com a participação de professores, sindicatos e comunidade educacional; deve atender princípios de eqüidade, transparência e justiça para ter credibilidade; é necessário criar uma imagem construtiva da avaliação a favor do professor e de sua atuação profissional; a avaliação docente deve articular-se com a avaliação da escola; a avaliação deve concorrer para a melhoria da qualidade da docência (UNESCO, 2007, p.21-22).
\end{abstract}

E na implantação de avaliação de desempenho, ainda segundo a Unesco (2007), devem ser tomados alguns cuidados, pois, "seu elevado custo se realizada com base em critérios de baixa qualidade; o modelo de avaliação adotado pode determinar a forma de atuar dos docentes; se não for consensual, poderá ter problemas na aplicação" (UNESCO, 2007, p.21) e se não for transparente e tecnicamente impecável, pode não ter credibilidade.

Fica claro que a educação é tomada como centralidade nas soluções dos problemas econômicos do país e os mecanismos para a eficiência da educação é torna-la competitiva, como ocorre no mundo corporativista. "As recomendações internacionais orientavam a reconfiguração da relação entre o Estado por meio da implementação de políticas de descentralização na gestão da educação e de incorporação da lógica da gestão privada na gestão pública" (KRAWCZYK, 2010, p.10). A educação passa a ditar normas do empresariado e os profissionais da educação passam a receberem normas de eficiência e competitividade.

A educação, conforme preconiza Mészaros (2006), deve ir para além do sistema da lógica capitalista. Não podemos pensar em mudança na educação se não pensarmos primeiro na estrutura do nosso quadro social. Para o autor, as mudanças que ocorrem na educação servem apenas para aliviar os efeitos desastrosos que o próprio capital cria, e não servem para uma mudança brusca e revolucionária no nosso sistema econômico.
Encerra-se salientando, nestas conjunturas, que o professor assemelhasse aos outros profissionais da sociedade que luta por melhores condições de trabalho e reconhecimento da função.

\section{CONCLUSÕES}

Uma das funções do professor é de promover o desenvolvimento da emancipação humana do aluno enquanto ser social, a fim de ampliar a sua capacidade de compreensão e leitura histórica da sua realidade, para que se compreendam os contrastes e determinações sociais e econômicos, determinantes na história dos homens. A partir das reformas educacionais nos anos de 1990, o papel do atual professor ultrapassou a função de ensinar. A configuração do modelo de professor passou a ser regido por um papel mais amplo: de gestor, líder educacional, ele passa a ter multifunções relacionando-se também com questões sociais que, como dissemos, ultrapassam o objetivo docente.

Cabe aos profissionais da educação a compreensão dessas mudanças para encontrar caminhos das alternâncias. Nestas novas recomendações o professor tem um papel fundamental de receptor e executor das propostas e é o principal agente afetado por elas. É necessário ter uma vigilância sobre os direitos sociais que foram instituídos em Lei e já conquistados pelos professores que estão constantemente entrando em cheque com o discurso do racionamento, eficiência, "fazer mais com menos". Está cada vez mais constante por todo o Brasil a paralizações dos professores que tentam manter os direitos já adquiridos pela classe.

Concordamos com as autoras Evangelista e Shiroma (2007) quando salientam que o professor é um dos maiores obstáculos das reformas educativas, acreditamos que ele tem o potencial para isto e ainda mais, goza de condições para desmascarar as reformas educacionais que vem dos Organismos Internacionais de modo a orientar a população sobre $o$ assunto.

A retórica dos documentos analisados se assemelha a do empresariado, com o discurso de eficiência para o professor que consiga atingir as metas de aprendizado. Buscam, estas reformas, um professor automatizado, sem a leitura de mundo, sem a teoria necessário que é essencial de sua profissão, sem a práxis necessária para sua transformação social. Um desafio para o 
professor, neste cenário, deve de ser a manutenção de seu papel histórico, mediador do conhecimento histórico, crítico e consciente de suas funções sociais escolares. Deverá saber ler nas entrelinhas o real significado das recomendações política presentes nos documentos norteadores das políticas e gestão educacional. Cabe aos profissionais da educação a compreensão dessas mudanças para encontrar os reais caminhos das transformações efetivas que promovam a educação e o ser professor no Brasil.

\section{REFERÊNCIAS}

BBC. PIB do Brasil pode crescer '7 vezes' com educação para todos, diz OCDE. 2015. Disponível em:

<http://www.bbc.com/portuguese/noticias/2015 /05/150512_educacao_mapas_cc>. Acesso em: 23 fev.2017.

BRASIL. Plano Diretor da Reforma do Aparelho do Estado. Brasília-DF, 1995. Disponível em: <http://www.bresserpereira.org.br/documents/ mare/planodiretor/planodiretor.pdf> Acesso em: 04 Fev. 2017.

DALE, Roger. Globalização e educação: demonstrando a existência de uma "cultura educacional mundial comum" ou localizando uma "agenda globalmente estruturada para a educação"? Educação \& Sociedade, Campinas, v. 25, n. 87, p. 423-460, maio/ago. 2004

DAMÁSIO, Maria Lúcia Francisco. Impacto das diretrizes internacionais nas políticas públicas educacionais brasileiras. Revista Novas Ideias, Recife, v. 1, n. 1, p. 7-24, jan. jun. 2008.

EVANGELISTA, Olinda; SHIROMA, Eneida Otto. Professor: protagonista e obstáculo da reforma. Educação \& Pesquisa, São Paulo, v.33, n.3, p.531541, set./dez.2007. https://doi.org/10.1590/S1517970220070003000 $\underline{10}$

GAJARDO, Marcela. Reformas educativas na América Latina: balanço de uma década. Documentos PREAL, n. 10, jul. 2000.

HARVEY, David. O neoliberalismo: história e implicações. 2. ed. São Paulo: Edições Loyola, 2011.
KRAWCZYK. Nora Rut. A reforma educacional na América Latina nos anos 90: uma perspectiva histórico-sociológica. Revista Latinoamericana de Educación Comparada, v.1, n.1, p. 10-17, 2010. Disponível em: <http://www.saece.com.ar/ relec/revistas /1/art1 .pdf> Acesso em: 14 nov. 2017.

MASCARO, Alysson L. Estado e forma política. São Paulo: Boitempo, 2013.

MÉSZAROS, István. A educação para além do capital. São Paulo: Boi Tempo Editorial, 2006.

MOREIRA, Jani Alves da Silva. Políticas de financiamento e gestão da educação básica (1990-2010): os casos Brasil e Portugal. MaringáPR: $\quad$ Eduem, 2015. https://doi.org/10.7476/9788576286547

PAULO NETTO, José; BRAZ, Marcelo. Economia política: uma introdução crítica. 8. ed. São Paulo: Cortez, 2012.

OLIVEIRA, Dalila Andrade. Regulação das políticas educacionais na América Latina e suas consequências para os trabalhadores docentes. Educação \& Sociedade, Campinas, v. 26, n. 92, p. 753-775, 2005. Disponível em: <http://www.scielo.br/pdf/es/v26n92/v26n92a0 3.pdf>. Acesso em: 14 out. 2017.

PEREIRA, Luiz Carlos Bresser. A crise da América Latina: consenso de Washington ou crise fiscal? Revista Pesquisa e Planejamento Econômico, Rio Janeiro, v. 21, n. 1, p. 3-23, abr. 1991. Disponível em:

<http://www.bresserpereira.org.br/papers/1991/ 91-criseamericalatina.pdf $>$. Acesso em: 14 out. 2017.

PEREIRA, Luiz Carlos Bresser; GRAU, Nuria Cunill. Entre o estado e mercado: o público não-estatal. Rio de Janeiro: FGV, 1999. p. 15-48. Disponível em:

$<$ http://www.reformadagestaopublica.org.br/pap ers/1998/84PublicoNaoEstataRefEst.p.pg.pdf>. Acesso em: 14 nov. 2017.

SHIROMA Eneida Oto; CAMPOS Roselane Fátima. GARCIA, Rosalba Maria Cardoso. Decifrar textos para compreender a política: subsídios teóricosmetodológicos. Perspectiva, Florianópolis, v.23, n.02, p. 427-446, jul/dez.2005. Disponível em: 
<https://periodicos.ufsc.br/index.php/perspectiv a /article /vi ew /9769/8999>. Acesso em: 14 nov. 2017.

UNESCO. Declaração Mundial Sobre Educação para Todos. Jomtien, Tailândia, 5 a 9 de março de $1990 . \quad$ Disponível em: <http://unesdoc.unesco.org/images/0008/00086 2/086291por.pdf>. Acesso em: 02 fev. 2017.

UNESCO. Educação para Todos: o compromisso de Dakar. Senegal, 26 a 28 de abril de 2000. Disponível em: <http://unesdoc.unesco.org/images/0012/00127 5/127509porb.pdf>. Acesso em: 14 nov. 2017.

UNESCO. O Desafio da Profissionalização Docente no Brasil e na América Latina. Brasília, março de 2007. Disponível em: <http://unesdoc.unesco.org/images/0015/00150 1/150121por.pdf>. Acesso em: 14 nov. 2017.

UNESCO. Educação um tesouro a descobrir: relatório para UNESCO da comissão Internacional sobre a Educação para o século XXI. Jacques Delors. Paris, UNESCO, 2010. Disponível em: <http://unesdoc.unesco.org/images/0010/00109 5/109590por.pdf> Acesso em: 24 mai. 2018.

Recebido para publicação em: 03/10/2017

Revisado em: 06/11/2017

Aceito em: 18/01/2017 